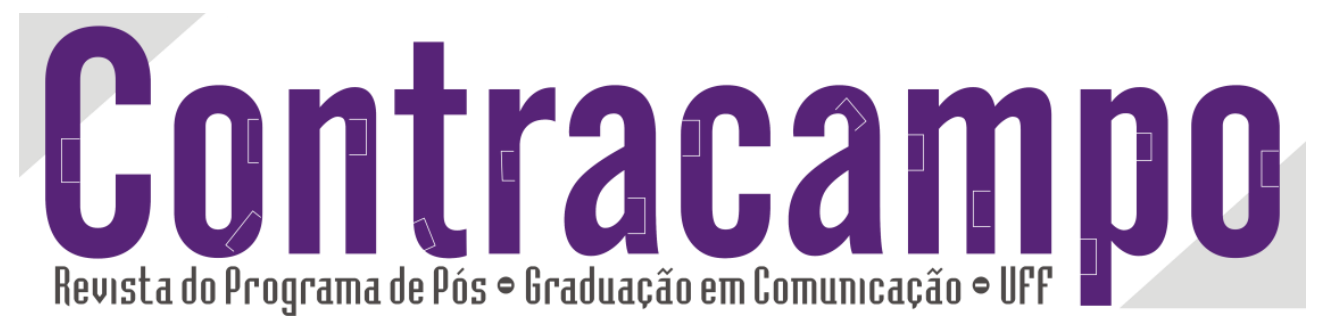

\title{
Narrativas Complexas na Ficção Televisiva ${ }^{1}$
}

\section{Complex Narratives in TV Fiction}

1 Uma versão reduzida deste artigo foi apresentada no GP Ficção Seriada do XXXV Congresso Brasileiro de Ciências da Comunicação Fortaleza, CE - 3 a 7/9/2012.

\section{Maria Cristina Palma Mungioli \\ crismungioli@gmail.com}

Professora do Depto. de Ciências da Comunicação da ECA-USP e do Programa de Pós-Graduação em Ciências da Comunicação da USP

Christian Pelegrini christian.pelegrini@gmail.com Doutorando em Meios e Processos Audiovisuais pela ECA-USP, Professor da PUC-SP.

Ao citar este artigo, utilize a seguinte referência bibliográfica

MUNGIOLI, Maria Cristina Palma. PELEGRINI, Christian. Narrativas Complexas na Fiç̧ão Televisiva. In: Revista Contracampo, v. 26, n. 1, ed. abril, ano 2013. Niterói: Contracampo, 2013. Pags: 21-37.

Enviado em: 07 de jan. de 2013 Aceito em: 14 de jan. de 2013

\section{PPGCOM $=$ UFF}

Contracampo

Niterói (RJ), v. 26, n. 1, abril/2013

www.uff.br/contracampo

A Revista Contracampo é uma revista eletrônica do Programa de Pós-Graduação em Comunicação da Universidade Federal Fluminense e tem como objetivo contribuir para a reflexão crítica em torno do campo midiático, atuando como espaço de circulação da pesquisa e do pensamento acadêmico. 


\section{Resumo}

Este artigo aborda alguns aspectos da ficção seriada de televisão que vêm delineando, segundo diversos estudiosos, uma estrutura narrativa complexa e inovadora para os formatos televisivos, sobretudo os de origem estadunidense. Em um primeiro momento, o texto discute as séries de ficção com base em um quadro complexo de interpretação do texto televisivo estabelecido a partir da materialidade do texto (histórica, social, composicional), das condições de produção e da produção de sentidos. Em um segundo momento, analisa-se a complexidade narrativa da série ForçaTarefa (TV Globo).

Palavras-chave: Narrativas complexas na televisão; séries de televisão; ficção televisiva.

\section{Abstract}

This article approaches some aspects of serial fiction television that, according to some scholars, features a complex narrative structure that demonstrates the formats innovation for the television serial fiction, especially those originated from U.S.A. The analysis takes in consideration fiction series based on a complex interpretation of the text television set from their materiality (historical, social, compositional), from production conditions and from the production of meanings. After this discussion, we observe the complex narrative in a serial production from Brazil through the analysis of some elements of Task Force (Globo TV).

Keywords: Narrative complexity in television, TV series, TV fiction. 
$\mathrm{N}$ as duas últimas décadas, as narrativas seriadas de televisão vêm apresentando transformações que se caracterizam pela complexificação em termos estruturais e estilísticos conforme Ang (2010), Mittell (2006), Sepulchre (2010), Jost (2011). As mudanças observadas, tanto em termos de estruturação do roteiro quanto em termos de procedimentos fílmicos e discursivos, configuram modos de fruição e interpretação cada vez mais ancorados na compreensão de um leitor de segundo nível (Eco, 1997).

Com o objetivo de discutir tais transformações, analisamos aspectos composicionais e estilísticos das narrativas de ficção seriada da televisão contemporânea e sua repercussão na série brasileira Força-Tarefa ${ }^{1}$ (Rede Globo, 20092011). Este artigo também nos permite dar continuidade às reflexões iniciadas em outro texto (Motter e Mungioli, 2006) no qual defendíamos a necessidade de se pensar a serialidade com base em parâmetros que a distanciassem da simples compreensão de que são meras repetições características da indústria cultural que dela faz uso para obter mais lucro. Sem esquecer a importância do fator econômico, afirmávamos que o formato/gênero seriado deveria ser considerado dentro de um quadro complexo de interpretação do texto televisual, ou seja, dentro de um quadro que levasse em conta a materialidade do texto (histórica, social, composicional), as condições de produção, o sujeito do discurso.

Consideradas na perspectiva histórica das produções literárias, as narrativas complexas têm no romance moderno e em seu precursor, D. Quixote, o seu "grau zero" (CALATRAVA, 2008). Observa-se em narrativas ditas complexas algo além do mero enredo, mas uma dimensão autorreferencial sobre o processo narrativo, na escritura do texto, no jogo das instâncias e sujeitos da enunciação, na dinâmica metafórica e nas relações intertextuais que mobiliza (CALATRAVA, 2008).

No audiovisual, tais elementos de complexificação comparecem na substância e na forma do discurso narrativo, tendo a câmera e os pontos de escuta como mediadores entre história e espectador (MONACO, 2009). Monaco (2009) enfatiza, ainda, a peculiaridade de a ficção seriada ser o veículo mais adequado para narrativas mais longas (inviáveis nos filmes).

\footnotetext{
${ }^{1}$ Produzida pela Rede Globo, a série policial foi escrita por Fernando Bonassi e Marçal Aquino e teve direção de José Alvarenga Jr. e Márcio Bandarra. Força-Tarefa teve três temporadas de 2009 a 2011.
} 
No entanto, ao discutirmos a complexidade da narrativa ficcional seriada em televisão, é adequado recusar a visão de que se trata da mera consequência de roteiros mais longos ou da apropriação da estética literária pela televisão.

Trata-se, na verdade, de um conjunto de fatores sociais, econômicos e tecnológicos cujas ressonâncias intra/extratextuais podem ser observadas no discurso ficcional televisivo, principalmente, a partir do final da década de 1970. Tais ressonâncias não ocorrem apenas nas séries norte-americanas, mas também na produção de ficção de televisão de outros países fortemente influenciada pelos padrões da indústria televisiva norte-americana. São transformações que envolvem o circuito da comunicação (HALL, 2002) e, portanto, constroem práticas, conceitos, códigos na forma de retroalimentação em que as questões simbólicas não se desvinculam das práticas sociais e condições de produção.

Em uma primeira aproximação, pode-se dizer que as transformações na ficcionalidade televisiva seriada atuam na composição do interdiscurso ${ }^{2}$ e podem ser notadas na hibridização dos gêneros e formatos ficcionais, dos gêneros discursivos (BAKHTIN, 2003) e no acabamento temático ${ }^{3}$ (BAKHTIN, 2003). Algumas dessas transformações são discutidas a seguir.

\section{Narrativas complexas nas séries de televisão}

Ang (2010) enfatiza a importância de Dallas e Dynasty para a complexificação das ficções televisivas não apenas pela utilização de estratégias narrativas diferenciadas em termos de construção da trama - entre elas o uso da ironia -, mas também, e, talvez, principalmente, no caso de Dallas, pelo surgimento de uma nova forma de recepção caracterizada por aquilo que a autora denomina "prazer irônico". Para a pesquisadora,

\footnotetext{
${ }^{2}$ Adota-se a definição de interdiscurso apresentada por Eni P. Orlandi, in Análise de discurso: princípios e procedimentos, segundo a qual o interdiscurso se estabelece a partir das relações entre memória e discurso. O interdiscurso é “(...) definido como aquilo que fala antes, em outro lugar, independentemente. Ou seja: é o que chamamos de memória discursiva: o saber discursivo que torna possível todo dizer e que retorna sob forma do pré-construído, o já-dito que está na base do dizível, sustentando cada tomada de palavra."

${ }^{3}$ Tanto o discurso quanto o acabamento temático do enunciado, na perspectiva de Bakhtin (2003), estão intrinsecamente relacionados à situação histórica concreta em que os mesmos ocorrem. De acordo com o autor, o acabamento temático de uma obra artística deve ser analisado, não apenas em função daquilo que os autores dizem a respeito dela, mas, sobretudo, pela própria obra de arte que dialogicamente incorpora os elementos sociais e psicológicos e os trata esteticamente.
} 
essa maneira de assistir constitui um distanciamento mais intelectual, com o sujeito numa posição superior, permitindo-se obter prazer e ao mesmo tempo expressar consciência da suposta baixa qualidade do mesmo. A ironia era, portanto, uma maneira de se relacionar com Dallas (...). A ironia, em resumo, é uma forma de capital cultural que autoriza aqueles que a possuem a estabelecer uma relação relativista com a televisão, esses espectadores reconhecem seus prazeres, mas não estão completamente sucumbidos aos mesmos; conhecem bem seus truques textuais e, portanto, podem brincar com eles através do bom humor. (ANG, 2010, p. 88)

A ironia e o sarcasmo observados intra e extratextualmente em Dallas e Dinasty tornaram-se, nas ficções seriadas norte-americanas desde os anos 1990, tanto um elemento estrutural no acabamento temático e na construção de personagens (intratextual) quanto uma estratégia de recepção (extratextual) (ANG, 2010). ${ }^{4}$ Essa nova abordagem, como a própria autora ressalta, não se restringiu às ficções produzidas nos E.U.A., mas se disseminou por diversos países que passaram a adotar o padrão melodramático de Dallas em suas produções nacionais, evidenciando o processo de glocalização no qual ocorre a “(...) nacionalização de convenções e gêneros importados para atender os gostos culturais, saberes e preocupações locais” (ANG, 2010, p. 92).

Para Jost (2011), a dimensão cultural das séries de televisão também pode ser observada por meio da importância e legitimidade que, principalmente, as séries norteamericanas adquiriram nos últimos anos entre os telespectadores e nos estudos de comunicação. A partir desse novo status, "a seriefilia substituiu a cinefilia e, mesmo se diferenciando dela, adquiriu alguns de seus traços: o conhecimento preciso das intrigas, das temporadas, dos atores, de suas carreiras, dos autores, de suas trajetórias e dos acasos da realização de seus projetos, datas de exibição, etc.” (JOST, 2011, p. 4-5). Para o estudioso francês,

o sucesso das séries [norte-americanas] se explica menos por sua capacidade de espelhar de maneira realista nosso mundo do que por sua capacidade de fornecer uma compreensão simbólica. Assim, é preciso vê-las como sintomas de nossas aspirações e por aquilo que elas dizem de nós. (Jost , 2011, p. 62)

\footnotetext{
${ }^{4}$ Essa perspectiva relaciona-se com o conceito horizonte de expectativa de Jauss (2005), pois se baseia na compreensão de uma obra a partir de ao menos três dimensões intrinsecamente relacionadas: gênero (filiação genérica, características genéricas), estética (forma e conteúdo) e pragmática (conhecimento dos usos e das linguagens relacionadas à ficcionalidade e à realidade).
} 
Em termos estruturais, para Mittell (2006), a complexificação surgida nas últimas duas décadas ocorreu pela hibridização das formas seriadas clássicas (a episódica e a contínua). Nesse entrelaçamento, a narrativa se constrói com a complexidade do tempo presente e de suas relações com o passado e com o futuro do universo diegético. Para o autor, Seinfield, The X-Files, Lost, West Wing seriam exemplos dessa transformação em cuja origem não estaria a influência do cinema ou da literatura, mas sim a própria evolução da linguagem da televisão.

Mittell (2006) enfatiza ainda que a complexidade não é garantia de audiência (ou mesmo de qualidade), mas abre um leque de possibilidades criativas e estéticas que são próprias da ficção seriada televisual. $\mathrm{Na}$ origem de tais transformações estaria a tensão entre as práticas institucionalizadas da televisão e a ação de "forças históricas que trabalham para transformar as normas estabelecidas com alguma criatividade." (MITTELL, 2006, p.30) Fatores como a crescente legitimação da televisão como meio narrativo, a autonomia de criadores e roteiristas e mesmo a competição com reality shows serviram de catalisadores para tais mudanças. Além disso, os novos suportes digitais (das coleções de DVDs à web) alteraram o processo de recepção dos programas de forma a permitir novos arranjos narrativos, gerando um aumento considerável de receita para as produtoras e criando condições mais efetivas para a seriefilia.

Da soap opera à série do prime time

Dallas e Dinasty são consideradas por Ang (2010) como soap operas do prime time, cujo sucesso, principalmente da primeira, fez com que o apelo melodramático e a estrutura baseada em personagens e nos relacionamentos interpessoais - características da soap opera - fossem estendidos para outros gêneros e formatos ficcionais do prime time. Além disso, deve-se considerar que a chegada de novas tecnologias de gravação e distribuição (VHS, DVD, TiVo) e dos canais a cabo fez com que o modelo adotado pelas grandes redes - no qual o horário da tarde era destinado a produções de menor orçamento e o prime time às produções de custo mais elevado - começasse a ruir. A possibilidade de o telespectador assistir aos programas em horário diferente daquele em que a emissora os exibe coloca em cheque todo o princípio organizador da grade de 
programação e lança novos desafios para os escritores e produtores de ficção televisiva (GANZ-BLAETTLER, 2011).

Nesse cenário, ganham espaço narrativas ficcionais que mesclam estratégias originalmente usadas pelas soap operas, que vão se complexificando com o objetivo de fazer frente às expectativas do público da TV a cabo, considerado menor, mais homogêneo e fiel, porém mais sofisticado (GANZ-BLAETTLER, 2011). Ainda em termos estruturais, a relação episódica (baseada na lógica da causa e consequência) e temporal da trama sofre um tratamento mais complexo por meio de elipses, prolepses e analepses. ${ }^{5}$ Tais procedimentos discursivos são muitas vezes acompanhados pela narração de uma voz over que, em geral, segundo Jost (2011), não é empregada apenas para esclarecer algum detalhe, mas principalmente para expressar sentimentos ou verdades gerais.

Essas transformações de natureza discursiva não se não se limitam à série propriamente dita, mas operam numa perspectiva de comunicação discursiva que envolve o interdiscurso, proporcionando comparações, contraposições, enfim, exigindo do telespectador uma interpretação de segundo nível (ECO, 1997), baseada não apenas na compreensão dos conflitos, mas também nas estruturas que constroem esses conflitos.

Serialização e folhetinização: formato, enredo e personagem

A serialização da ficção televisiva norte-americana importou convenções e práticas da ficção seriada radiofônica (além de escritores, elencos e mesmo programas inteiros). Embora não fosse o único formato de ficção (havia, por exemplo, os teleteatros), rapidamente as formas seriadas ganharam importância estratégica em um meio que já nasceu como indústria, privilegiando lógicas de racionalização da produção (MITTELL, 2010).

\footnotetext{
${ }^{5}$ Elipses, prolepses e analepses são recursos que relacionam temporalmente os dois níveis da narrativa: fabula e sujet (enredo). Na elipse, certo tempo da fábula - e consequentemente os eventos ocorridos nele simplesmente não é mostrado no enredo, é omitido do receptor; na analepse, a ordem temporal da fábula é revertida no enredo, retrocedendo para mostrar o passado (este é o popular flashback); nas prolepses o tempo da fábula é antecipado em trechos do enredo, mostrando momentos futuros (este é o menos usual flashfoward). Ver REIS, Carlos e LOPES, Ana C. Dicionário de Narratologia.Coimbra, Ed. Almedina, 2007.
} 
A tradição da ficção televisual americana possui duas formas básicas de serialização: a serial e a serie. Serial (que, no Brasil, corresponderia à série) é o modo em que a narrativa acontece ao longo de episódios, com arcos dramáticos que atravessam diversos capítulos até uma conclusão. É a forma que predomina, por exemplo, nas telenovelas brasileiras. No caso do serial tipicamente americano, geralmente, os limites do arco dramático ocorrem dentro de uma temporada anual. Já a serie (que corresponderia ao nosso seriado) é a forma em que os arcos dramáticos têm o limite do episódio - o desequilíbrio dramático ocorre no início do episódio e é resolvido no mesmo episódio.

Nos anos recentes, tem-se observado uma crescente hibridização das duas modalidades de serialização. Mais que classificações categóricas, serial e serie tornaram-se polos de um eixo ao longo do qual são encontradas ficções que possuem características de um e de outro tipo. O já mencionado Arquivo $X$ é exemplo claro dessa hibridização. Na maior parte dos episódios, observamos um mistério sobrenatural apresentado na abertura fria ${ }^{6}$ e os protagonistas buscando resolvê-lo nos 44 minutos que se seguem. Há, no entanto, episódios que versam sobre motivos (TOMACHEVSKI, 1976) ligados ao tema e que se estendem ao longo das temporadas de Arquivo X. Uma possível conspiração governamental para encobrir contatos com alienígenas ou ainda historias de relacionamentos entre personagens e mesmo personagens de episódios passados que, mesmo não sendo personagens fixos, retornam com todo seu histórico construído na primeira aparição constituindo a narrativa cumulativa.

Para Mittell (2006), a forma mais básica de complexidade narrativa ocorre na mudança de equilíbrio entre serie e serial. Nesse aspecto, a complexidade narrativa abre possibilidades criativas que resgatam o melhor das duas formas. Assim, nesse novo equilíbrio, a narrativa episódica permite a sensação de completude e a catarse esperada na resolução de problemas pontuais; enquanto a serial possibilita o desenvolvimento de tramas que não caberiam nos limites temporais de um único episódio ${ }^{7}$. Essa nova

\footnotetext{
${ }^{6}$ Abertura fria (cold opening) é o trecho do programa que é mostrado antes mesmo da vinheta de abertura e, em geral, logo em seguida aos créditos do programa anterior. Dada a necessidade de manutenção da audiência, a abertura fria cumpre a função de núcleo do primeiro ato aristotélico e prende o espectador ao programa que se iniciará.

${ }^{7}$ Tal assimilação de um tempo realista é bem retratada pelo produtor de ER, John Wells (apud Carlos, 2006, 42): "Não fizemos um único episódio sobre a morte da mãe do Dr. Benton. A morte dela durou
} 
estrutura dá margem a novos modos de interação entre a produção e a audiência, que colocam em marcha processos de produção de sentido por meio dos quais podem ser identificados, de acordo com o nosso entendimento, telespectadores de primeiro e de segundo nível à semelhança dos leitores de primeiro e de segundo nível de Eco $(1997)^{8}$. Para Johnson (2005), os telespectadores que conhecem a trama, seu universo narrativo e seus aspectos de estilo sentem-se como se estivessem sendo cumprimentados pelo autor em meio à multidão, ratificando a sensação de que são parte de um grupo seleto que entende os detalhes e as ramificações do que está sendo mostrado. Cabe lembrar que esse processo é muito bem visto pelos produtores, pois, de certa maneira, protege a série e a emissora da forte concorrência de outras emissoras e mesmo de outras atividades do telespectador.

Assim, a complexidade narrativa concretiza-se de maneiras diferentes - e por motivos diversos - em programas de gêneros variados, mas seu sucesso frente à fiel audiência pode estar ligado à própria natureza do discurso narrativo como sugere Culler:

(...) o prazer da narrativa está ligado ao desejo. Tramas falam do desejo e o que recai sobre ele, mas o movimento da narrativa em si é levado pelo desejo em forma de "epistemofilia", um desejo de conhecer; nós queremos descobrir segredos, saber o final, encontrar a verdade. (CULLER, 2009, p. 126),

Ou, ainda, de acordo com Mittell (2010, p. 217), "parte do prazer de assistir a narrativas pode ser o ato de amarrar fios narrativos aparentemente desconectados (...)". A descoberta do prazer de se entender como as tramas vão se entrelaçar e o que vai acontecer a seguir transformou o mercado de ficção seriada americana nos últimos anos. O caso mais conhecido, e mais bem sucedido, é $L O S T$, em que a complexidade narrativa ocorre em sua plenitude ao construir como premissa as incongruências da sobrevivência à queda de um avião, mas também a todas as outras peculiaridades da misteriosa ilha. No entanto, para além do mero conteúdo misterioso que se coloca ao espectador como jogo a ser solucionado, LOST incorpora a estética do quebra-cabeça à sua dimensão formal. Mais do que a simples quebra de linearidade narrativa, LOST abusa de prolepses

onze episódios porque é assim que as coisas realmente acontecem. (...) Não fizemos um episódio sobre o término do casamento do dr. Greene porque casamentos não terminam num só dia."

${ }^{8}$ Para Eco (1997), o leitor de primeiro nível caracteriza-se por compreender o texto em seu sentido estrito; já o leitor de segundo nível estabelece relações, não se limita apenas a compreender o texto, mas também a relacioná-lo com as intenções do autor, a indagar-se sobre o significado não imediato das palavras, das cenas, enfim da obra literária ou artística. 
e analepses, personagens desconhecidos que assumem a focalização e mostram elementos da trama até então desconhecidos, ou ainda sugere ontologias e universos paralelos onde ocorre a trama (BOOTH, 2010). Parte do prazer de assistir à série está em tentar descobrir que tempo é aquele, ou que função tem uma personagem dentro da trama ou a que universo pertence e, até mesmo, que universo vemos na tela (CORDEIRO, 2007). É certo que LOST não inventou tais estratégias, no entanto, a intensidade e frequência de seu uso demandam do espectador competências de um leitor cada vez mais apto a compreender não apenas a gramática, mas também a sintaxe de uma narrativa multiforme.

Contempla-se não só a imersão na diegese, mas a própria construção da narrativa. Busca-se compreender como a engrenagem narrativa funciona (MITTELL, 2006). Embora todas as tentativas de clonagem de LOST não tenham obtido sucesso, elementos de sua complexidade narrativa incorporaram-se ao repertório da TV americana. Breaking Bad é um programa com estrutura bastante próxima à serial. Na primeira temporada, a abertura fria de cada capítulo abusava do in media res ao mostrar uma imagem que convidava o telespectador a assistir e descobrir o que a imagem significava na trama do episódio que então se iniciava (COULTHARD, 2010). Na segunda temporada, no entanto, a maioria das aberturas frias mostrava misteriosas imagens que não surgiriam no episódio que seria apresentado a seguir, mas que, aos poucos, construíam uma cena que só aconteceria no final da temporada.

Também as sitcoms recorrem à complexidade narrativa. Em How I Met Your Mother, desde o primeiro episódio, vemos, em 2030, o protagonista contando aos filhos adolescentes como ele havia conhecido sua mãe. A narrativa então se desdobra em histórias com arcos bem delimitados ao próprio episódio que sempre mostram o protagonista diante de situações românticas. Como as histórias não se referem a fatos no tempo presente do enunciador, mas a lembranças do passado contadas por ele aos filhos (e aos telespectadores), criam-se condições para a suspeição do próprio relato, pois se trata de uma história dentro da outra (narrativa encaixante e narrativa encaixada) em que o narrador-protagonista conta a história a partir de seu próprio ponto de vista. O que pode levar o telespectador ao distanciamento do "prazer irônico" (ANG, 2010), demarcando novos limites de interpretação de um leitor de segundo nível (ECO, 1997). Assim, alguns fatos são enaltecidos enquanto outros são encobertos. A principal peça do 
quebra-cabeça proposto ao telespectador refere-se ao desafio de tentar adivinhar se o interesse romântico do protagonista por uma mulher - o que ocorre na maioria dos episódios - culminará por desvendar o mistério (para o telespectador) em torno da identidade da mãe dos adolescentes. Esse desafio constante obriga o telespectador a resgatar informações fornecidas ao longo das temporadas, interpretando-as à luz do que ocorre durante o episódio a que assiste. Um quebra-cabeça em que a fórmula episódica incorpora elementos da narração serial.

Em termos de construção de personagens, os arcos narrativos mais longos possibilitam por meio da criação de intrigas mais complexas o desenvolvimento de narrativas cumulativas. Para Newcomb (apud GANZ-BLAETTLER, 2011), as narrativas cumulativas passam a ser traço característico de algumas séries norteamericanas a partir de Magnum. As narrativas passam a ser cumulativas na medida em que fatos ocorridos em episódios precedentes não são esquecidos e podem ser retomados com a finalidade de dar uma nova luz sobre um tema ou assunto. Assim, personagens passam a ter memória e se ressentem de fatos ocorridos no passado ao mesmo tempo em que temem pelo seu futuro diante de uma determinada situação dramática que se relacione ao que viveram.

Enfim, as intrigas se complexificam, os conflitos se expandem propiciando desfechos, às vezes, inesperados e que possibilitam mais de uma solução dramática. Um exemplo dessa estratégia discursiva pode ser observado em Ally McBeal no final da década de 1990. A protagonista imaginava (e o telespectador penetrava em sua consciência) as soluções que pretendia dar a seus problemas antes de se mostrar a solução "oficial" e politicamente menos incorreta. Esse procedimento de forte apelo dramático permitia toda a sorte de soluções politicamente incorretas - envolvendo ironia, sarcasmo, paródia - fornecendo elementos importantes para a caracterização da personagem e de sua visão de mundo. Nessa mesma linha, observa-se mesmo uma tendência à revalorização dos fluxos de consciência em séries posteriores. Scrubs talvez seja o exemplo mais evidente de tal fórmula narrativa. Ao longo de seu cotidiano, o protagonista tem fantasias variadas, mostrando o que poderia ou gostaria de ter feito em determinadas situações, imergindo em um mundo subjetivo.

Tais estratégias possibilitam a criação de personagens redondas (FORSTER, 1998), mais próximas do telespectador e de seu cotidiano que aquelas das séries de 
televisão até o final da década de 1970 nas quais predominavam personagens planas e, muitas vezes, com "conduta perfeita" (JOST, 2011). A humanização dos protagonistas permite uma maior identificação do telespectador com a personagem e um engajamento maior da audiência em relação à trama (JOST, 2011).

Alguns elementos para análise de Força-Tarefa

A seguir, analisamos alguns elementos das narrativas complexas encontrados na série Força Tarefa. As três temporadas da série Força-Tarefa ${ }^{9}$ narram os conflitos morais e psicológicos do Tenente Wilson (Murilo Benício), integrante de uma das equipes de investigação da corregedora militar da polícia do Rio de Janeiro. A série surge em 2009 no rastro do sucesso do filme Tropa de Elite, mas não devemos deixar de levar em conta o sucesso das séries norte-americanas do gênero policial como Criminal Minds, The Mentalist, Dexter, NCIS, Cold Case, CSI principalmente nos canais pagos.

Esteticamente, Força Tarefa apresenta características que a diferenciam de modelos de produção historicamente hegemônicos na ficção seriada da TV brasileira.

Se tradicionalmente os imperativos institucionais da televisão levavam a uma economia de produção que visava "a construção de espaços diegéticos sem pretensão, projetados para apresentar o máximo de narrativa tão eficientemente quando o orçamento, tempo e condições tecnológicas permitirem" (BUTLER, 2010, 12\%). Força Tarefa rompe com a linguagem anódina do estúdio, da onipresente iluminação high light e da videografia em multicâmera; há uma clara opção por uma tendência mais ampla de produzir TV com o mesmo apuro estético tradicionalmente reservado ao cinema. Fato que a diferencia de outras séries de sucesso da TV Globo também levadas ao ar na mesma época na faixa noturna de sua programação.

Embora Força Tarefa não seja nem a primeira nem a única série brasileira a utilizar externas, a produção de $70 \%$ das imagens do seriado nessas condições afeta visivelmente o resultado. A opção por externas não só acentua o realismo das ações policiais ${ }^{10}$ (tiroteios em ambientes fechados - casas, bares, becos de favelas - ou em

\footnotetext{
${ }^{9}$ A primeira temporada com doze episódios foi exibida de 16/04 a 02/07/2009. A segunda temporada teve 10 episódios e foi ao ar de 06/04 a 08/06/2010. A terceira temporada, com 8 episódios, foi exibida de 03/11 a 22/12/2011. A duração média dos episódios foi de 45 minutos.

${ }^{10}$ Outro exemplo de série brasileira também do gênero policial que utilizou efeitos especiais para dar mais realismo à narrativa foi A justiceira, criada por Daniel Filho, Antonio Calmon, Aguinaldo Silva e
} 
grandes espaços abertos - pedreiras, praias -, perseguições de carros ou de helicópteros), mas coloca diante dos produtores possibilidades (e exigências) concretizadas por meio de uma iluminação sofisticada, contrastante e dramática. A videografia já não mais se prende ao predomínio dos primeiros planos televisuais, mas ousa grandes planos gerais e estratégicos planos de detalhe. O papel da câmera como instância enunciadora ganha força. Também o papel da edição, que ao construir a narrativa a partir dos vários fragmentos de imagem, manipula o tempo das ações livremente, dando ritmo bem diferente do jogo plano-contraplano dos diálogos muitas vezes característicos da teledramaturgia brasileira. Nas cenas em que a Força Tarefa se reúne para discutir os casos de corrupção a serem investigados, a câmera na mão em planos fechados (primeiros e primeiríssimos) chicoteia de um personagem a outro, colocando o espectador muito próximo, como parte do círculo, confidente dos casos secretos discutidos pelo grupo. Nas cenas de ação, composições longitudinais explorando o rack focus (passagem de um plano a outro) mostram a integralidade da mise én scene em toda sua riqueza, mas dita ritmo e tensão ao colocar o conflito todo na tela.

A sofisticação no tratamento das imagens é acompanhada pelo tratamento discursivo que produz significação não apenas pelos diálogos ou pelos efeitos sonoros de explosões de bombas, mas também por dimensionar o "peso" intolerável do silêncio e das explosões de cólera durante as discussões em um lar fragmentado pela violência das situações-limite vividas pelo Tenente Wilson e sua companheira (Jaqueline, interpretada por Fabíula Nascimento). Os pontos de escuta salientam a premissa da série ao registrar, nas reuniões da equipe de investigadores de Força Tarefa, a fala discreta dos personagens, para quem está bem próximo e tem a autorização para ouvir os casos de corrupção da polícia. Esporadicamente, sirenes de polícia se ouvem bem ao fundo, distantes, como a reiterar que aquela não é a polícia comum, mas um grupo à margem, fora do ambiente sonoro das delegacias e quartéis. O restante dos sons tende a construir uma urbanidade sem delicadezas, quando mesmo o silêncio das cenas mantém o ruído de fundo do extra-campo. O ponto de escuta favorece os tiros (que, comparativamente, são mais fortes que as falas), tornando-os duros, crus, impactantes.

Doc Comparato, dirigida por Daniel Filho. A série de 12 episódios foi levada ao ar de 02/04 a 02/07/1997 pela Rede Globo. 
A sofisticação de Força Tarefa não se limita aos aspectos de estilo da linguagem audiovisual utilizada, mas ousa na própria dramaturgia ao propor o desenvolvimento dramático de personagens (e especialmente da personagem principal) de forma mais elaborada, mais carregada de nuances e conflitos internos. A complexidade da trama de Força Tarefa se evidencia por meio da construção de arcos narrativos que se desenvolvem ao longo de vários episódios em que o atormentado tenente Wilson precisa suplantar seus próprios medos e fantasmas para fazer frente a um universo marcado pela corrupção e pelo jogo em que o mais forte (e corrupto) geralmente vence. O tratamento temático, a estrutura do roteiro e a construção de personagens convergem para a criação de um universo ficcional asfixiante em que o protagonista deve fazer valer valores morais e éticos acima de seus anseios e desejos pessoais.

Em todas as temporadas, temos a presença de Jonas (Rogério Trindade), oficial da Polícia Militar, uma espécie de padrinho do tenente Wilson e tido por este como modelo de boa conduta na corporação. Porém, como sabemos desde o primeiro episódio da primeira temporada, ao ser flagrado por envolvimento em crimes pelo próprio tenente Wilson, Jonas suicida-se. A partir de então, Jonas que está presente em todos os episódios de todas as temporadas se converte em uma espécie de alter ego do tenente. Jonas torna-se um interlocutor implacável, que questiona com ironia e sarcasmo as atitudes e decisões do tenente contrapondo-o a seus medos, a seus fantasmas e, sobretudo, aos valores morais que devem presidir toda e qualquer decisão de um policial que deseja ser perfeito e incorruptível como seu tenente. Além disso, a presença desse "fantasma" e de seu riso irônico ao lado das demais personagens relembram ao Tenente que as pessoas fraquejam e que ele precisa superar essa condição humana se quiser continuar incorruptível. Dessa forma, ao longo das três temporadas, o arco narrativo iniciado no primeiro episódio se faz presente e acrescenta camadas de densidade dramática à trama ao mesmo tempo em que relaciona personagens e temas. Tanto a vida profissional quanto a familiar e amorosa do Tenente se constroem por meio de camadas em que os problemas e dramas se adensam conforme as temporadas são apresentadas.

A narrativa cumulativa ganha ainda camadas por meio de prolepses e analepses utilizadas tanto para mostrar com o auxílio de uma voz over como um crime foi desvendado - ou como um conflito familiar foi bem ou mal resolvido - como também 
para possibilitar versões alternativas da trama. Muitas vezes, o narrador da história é o criminoso ou comparsa dele como acontece no episódio Dupla Investigação (exibido em 17/11/2011), da terceira temporada, em que temos versões contraditórias sobre um assassinato. Ao telespectador resta comparar as versões, procurar falhas, encontrar contradições entre o mostrado e as provas conseguidas pela equipe de investigação. Procedimentos semelhantes aparecem em séries polícias e dramáticas norte-americanas como Criminal minds, The Mentalist, Dexter, NCIS, Cold case, CSI, Six Feet Under, Dexter etc.

Ainda na terceira temporada, outras camadas foram acrescentadas à narrativa que teve início com a promoção de Wilson a capitão e com a notícia de que toda a equipe de investigação das duas primeiras temporadas foi dizimada. Ao novo capitão coube encontrar os assassinos de sua equipe e tentar ganhar a confiança de seus novos subordinados. A busca pelos assassinos se constituiu como o grande arco narrativo dessa temporada que teve oito episódios, em que em cada um se resolve uma parte do quebra-cabeça. A resolução final de toda a intriga dessa temporada ocorrerá no último episódio com a captura e prisão dos policiais culpados pelo extermínio da equipe de investigação.

\section{Considerações finais}

Levando-se em conta os diversos aspectos anteriormente analisados, observa-se que a introdução de narrativas complexas nos formatos de ficção seriada, sobretudo nas séries, não decorre apenas da imaginação cada vez mais criativa de seus autores/produtores. O conjunto de transformações anteriormente discutidas refrata todo um conjunto de transformações que incide no circuito produção-circulaçãodistribuição/consumo-reprodução (Hall, 2002).

No que diz respeito à produção, constatamos, ao longo da discussão, que boa parte das mudanças envolveu a criação de universos narrativos mais complexos, que exigem dos telespectadores um envolvimento emocional e cognitivo mais apurado tanto em função do uso de diferentes temporalidades como em função de uma maior complexidade na construção de personagens e, portanto, de suas motivações e relações com outros personagens. 
Cabe destacar, no entanto, que esse envolvimento possui relação entre o prazer de conhecer, de desvendar, de vislumbrar, além da história, a própria construção textual e de reconhecê-la como um ato de criatividade que extrapola os limites do já-visto e do já-dito. O telespectador transforma-se em descobridor, alguém que procura "prestar mais atenção às estruturas e aos significados das cenas, pois a qualquer momento uma leitura de segundo nível poderá ser necessária" (MOTTER e MUNGIOLI, 2006). Unese o prazer de conhecer, reconhecer, descobrir os segredos - ou seja, a epistemofilia (CULLER, 2009) - ao prazer de se descobrirem os mecanismos que envolvem esses segredos, o que garante ao telespectador o status de connaisseurs.

\section{Referências bibliográficas}

ANG, Ien. A ficção televisiva no mundo: melodrama e ironia em perspectiva global. Matrizes. Ano $4, n^{\circ}$ 1, jul./dez. 2010.São Paulo.

BAKHTIN, Mikhail. Estética da Criação Verbal. São Paulo: Martins Fontes, 2003.

BOOTH, Paul. Memories, Temporalities, Fictions: Temporal Displacement in Contemporary Television. Television and New Media. $\mathrm{n}^{0}$ 12, 2010. Disponível em http://tvn.sagepub.com/content/12/4/370, capturado em 20/10/2012.

BUTLER, Jeremy. G. Television Style (Kindle Edition). New York, Ed. Routledge, 2010.

CARLOS, Cassio S. Em tempo real: Lost, 24 horas, Sex and the City e o impacto das novas séries de TV. São Paulo: Alameda, 2006.

CALATRAVA, José R. Valles. Teoría de la narrativa. Una perspectiva sistemática. Madri: Iberoamericana, 2008.

CORDEIRO, Tiago. Lost e o fim da TV. Superinteressante, abril de 2007, disponível em http://super.abril.com.br/superarquivo/2007/conteudo_486660.shtml, acessado em 02/11/2012.

COULTHARD, Lisa. The Hotness of cold opens: Breaking Bad and the serial narrative as puzzle. FlowTV. ${ }^{0}$ 13-03, volume 13, 2010. Disponível em http://flowtv.org/2010/11/thehotness-of-cold-opens/, acessado em 16/10/2012.

CULLER, Jonathan. Literary theory . New York: Sterling Publishing, 2009 ECO, Umberto. Innovation et répétition: entre esthétique moderne e post-moderne. In BEAUD, Paul \& QUÉRE, Louis (org.) Dossier: Les theories de la réception. Réseaux no. 68 CNET. 1994. Disponível em http://www.enssib.fr/autres-sites/reseaux-cnet/, capturado em 20.01.2006.

ECO, Umberto. Seis Passeios pelos Bosques da Ficção. São Paulo: Cia. das Letras, 1997. 
FORSTER, Edward Morgan. Aspectos do romance. São Paulo: Globo, 1998.

GANZ-BLAETTLER, Ursula. Récits cumulatifs et arcs narratifs. In: SEPULCHRE, Sarah (org.). Décoder les séries télévisées. Bruxelas: Éditions De Boeck Université, 2011

JAUSS, Hans Robert. Pour une esthétique de la réception. Paris: Gallimard. 2005.

JOHNSON, Steven. Everything bad is good for you: how today's popular culture is actually making us smarter. New York, Riverhead Books, 2005.

JOST, François. De quoi les séries américaines sont-elles le symptôme. Paris: CNRS Éditions, 2011.

MITTELL, Jason. Narrative Complexity in Contemporary American Television. The Velvet Light Trap. Number 58, Fall 2006, University of Texas Press.

MITTELL, Jason. Television and American Culture. New York: Oxford, 2010

MONACO, James. How to read a film. Movies, Media, and Beyond. New York: Oxford, 2009.

MOTTER, Maria Lourdes; MUNGIOLI, Maria Cristina Palma. Serialidade: o prazer de reconhecer e pré-ver. Communicare. Vol. 6 - no. 2 - 2006. São Paulo.

ORLANDI, E. P. Análise de discurso: princípios e procedimentos. Campinas/SP: Pontes, 1999.

REIS, Carlos \& LOPES, Ana C. Dicionário de Narratologia. Coimbra, Ed. Almedina, 2007.

SEPULCHRE, Sarah (org.). Décoder les séries télévisées. Bruxelas: Éditions De Boeck Université, 2011.

TOLEDO, Dionísio de Oliveira (org). Teoria da literatura: formalistas russos. Porto Alegre: Globo, 1976.

TOMACHEVSKI, B. Temática. TOLEDO, Dionísio de Oliveira (org). Teoria da literatura: formalistas russos. Porto Alegre: Globo, 1976. 